\title{
Neoliberalismo y transformaciones socio-espaciales en caletas urbanas del Área Metropolitana de Concepción. Los casos de Caleta Los Bagres y Caleta Cocholgüe, Tomé
}

\author{
Neoliberalism and socio-spatial transformations in urban coves of the Metropolitan Area of Concepción. The cases of \\ Caleta Los Bagres and Caleta Cocholgüe, Tomé
}

Rosa María Guerrero Valdebenito* y Mabel Loreto Alarcón Rodríguez**

Recibido: 26 de marzo de 2018

Aceptado: 19 de junio de 2018

\section{Resumen}

Las caletas de Chile son asentamientos litorales centrados en la pesca artesanal a pequeña escala, que conviven con sistemas urbanizados mayores -grandes infraestructuras, puertos y ciudades- lo que genera tensiones y amenazas a sus prácticas socioculturales, económicas y de habitabilidad tradicionales.

El articulo explora estas tensiones, centrándose en los casos de las caletas de Los Bagres y Cocholgüe, en la comuna de Tomé, Área Metropolitana de Concepción.

Para ello, propone comprender los procesos de transformación socioespacial de éstas caletas, y sus estrategias de adaptación a los efectos del modelo de desarrollo neoliberal.

La metodología de investigación es cualitativa, en base a un análisis social y espacial, incorporando técnicas de recolección de información como revisión de fuentes bibliográficas, realización de entrevistas semiestructuradas, levantamiento de campo, y procesamiento y análisis de los procesos de transformación y estrategias de adaptación, que se mapean y esquematizan. Las transformaciones se organizan en fases, acompañadas de mapas de interpretación del crecimiento urbano.

Los resultados han permitido reflexionar en torno a las fragilidades de las caletas en dos niveles. Primero, en su configuración interna como lugares que combinan vida y trabajo, ya que cuando merma el recurso que las hizo nacer, se pone en riesgo su sostenibilidad. Segundo, en su exposición a procesos de invisibilización o erradicación, que describen los niveles de integración de ellas a los entornos urbanos. Finalmente, ha permitido reflexionar en torno a la necesidad de preservar y poner en valor sus modos de vida y los espacios que dan cuenta de ellos, como parte central de la identidad y sostenibilidad de los territorios urbanos litorales del país.

Palabras clave: caletas urbanas, hábitat urbano, patrimonio pesquero, pesca artesanal.

\begin{abstract}
The coves of Chile are coastal settlements focused on small-scale artisanal fishing. Currently, they coexist with larger urbanized systemsmega infrastructures, ports, cities, etc.-which generate tensions and threats to traditional socio-cultural, economic and habitability practices. The article explores these tensions, focusing on the cases of Los Bagres and Cocholgüe in the municipality of Tomé, Metropolitan Area of Concepción.

To do this, it proposes to understand the socio-spatial transformation processes of the coves, and their adaptation strategies to the effects of the neoliberal development model.

The research methodology is qualitative, based on a combination of social and spatial analysis, incorporating information gathering techniques such as review of bibliographic sources, conducting semistructured interviews, field survey, and information processing and analysis, based on to the organization of transformation processes and adaptation strategies, which are mapped and schematized. This evolution is organized in phases, accompanied by interpretation maps of urban growth.

The results have allowed us to reflect on the fragilities of the creeks on two levels. First, in their internal configuration as places that combine life and work, because when the resource that gave birth to them is reduced, their sustainability is put at risk. Second, in its exposure to processes of invisibility or eradication, which describe the levels of their integration into urban environments. Finally, it has allowed us to reflect on the need to preserve and value their ways of life and the spaces that account for them, as a central part of the identity and sustainability of the coastal urban territories of the country.
\end{abstract}

Keywords: fishing heritage, small-scale artisanal fishing, urban coves, urban settlements.

\footnotetext{
* Departamento de Urbanismo, Facultad de Arquitectura, Urbanismo y Geografía de la Universidad de Concepción, Concepción, Chile. Contacto: rosaguerrero@udec.cl

** Departamento de Urbanismo, Facultad de Arquitectura, Urbanismo y Geografía de la Universidad de Concepción, Concepción, Chile. Contacto: $\underline{\text { mabelalarcon@udec.cl }}$
}

Las autoras quieren agradecer la colaboración de Catalina García y Eduardo Yáñez, ambos licenciados en Arquitectura de la Universidad de Concepción. Cómo citar: Guerrero, R. y Alarcón, M. (2018). Neoliberalismo y transformaciones socio-espaciales en caletas urbanas del Área Metropolitana de Concepción. Los casos de Caleta Los Bagres y Caleta Cocholgüe, Tomé. Revista de Urbanismo, 38, 117. http://dx.doi.org/10.5354/0717-5051.2018.48666 


\section{Introducción}

El borde costero de Chile se extiende por cerca de 55.000 km efectivos (Camus, 2001), con el Océano Pacífico como gran escenario. En él coexisten diversos tipos de asentamientos, asociados a diferentes escalas socioeconómicas y territoriales. Los de gran escala han configurado puertos (Martner, 1999), y complejos sistemas urbano-portuarios (Alarcón, 2016). Los de pequeña pequeña escala, se conocen en Chille como "caletas" (Marcucci, 2014), y corresponden a asentamientos costeros cuya economía y vida se ha articulado tradicionalmente en torno a la extracción artesanal de productos del mar. Ello ha generado diversas prácticas sociales y culturales que los identifican y diferencian de otras comunidades (Marcucci, 2014, McGoodwin, 2002; Gajardo y Ther; 2011), configurando a las caletas como importantes lugares geográficos, socio económicos y simbólicos (Saavedra y Macías, 2012; Sáez, 2004; Orellana y Díaz; 2016).

De acuerdo al Servicio Nacional de Pesca y Acuicultura (2013), en Chile existen 270 caletas pesqueras reconocidas por el Estado, de las cuales, al menos 75 se ubican en el borde costero de la Región del Biobío, siendo la segunda en cantidad a nivel nacional. La actividad extractiva que se desarrolla en ellas provee a las comunidades locales de recursos marinos frescos, contribuyendo a la salud y economía local, cumpliendo un importante rol para el desarrollo sostenible de los territorios. A nivel mundial, el $95 \%$ de los pescadores realiza su actividad a pequeña escala, capturando la mitad del pescado para el consumo humano a nivel global, lo que involucra a más de 200 millones de trabajadores (Mc Goodwin, 2002). No obstante, la riqueza económica, ambiental y sociocultural de estas comunidades, los espacios que ellas habitan, en el caso chileno, han sido históricamente precarios y vulnerables.

En el caso de la Región del Biobío, aunque la ocupación del borde costero se expandió principalmente durante el siglo XIX, asociada a la industria carbonífera y sus puertos (Salinas y Pérez, 2011), existen asentamientos litorales de antigua data, que originaron ciudades costeras como Penco o Tomé, entre otras. La industria textil y actualmente la forestal y metalúrgica, han determinado un borde costero intensamente urbanizado, configurando el Área Metropolitana de Concepción (AMC), la segunda área metropolitana a nivel nacional. En este territorio, las caletas están siendo presionadas por grandes infraestructuras -puertos, autopistas, instalaciones energéticas-, desarrollos inmobiliarios, etc.- $\quad$ que ponen en riesgo su sistema socio económico y espacial de base artesanal, familiar y comunitaria. Muchos habitantes de las caletas ven el futuro con incertidumbre, no visualizan sostenibilidad de los oficios asociados a la pesca, ni una valorización de sus formas de habitar. No obstante, ellos han implementado diversas estrategias de adaptación para preservar su hábitat e identidad, y el oficio que da forma a ambos.

Surge entonces la pregunta de ¿Cuáles han sido específicamente los procesos de transformación y estrategias de adaptación de las caletas para resistir las presiones del mercado? Para responder a esta pregunta, se plantea el objetivo general de comprender los procesos de transformación socioespacial de las caletas urbanas del Área Metropolitana de Concepción, y sus estrategias de adaptación a los efectos del modelo de desarrollo neoliberal.

Se plantea como hipótesis que las caletas son hábitats fuertemente tensionados por procesos como el crecimiento del capital industrial a gran escala, el desarrollo urbano de corte neoliberal, la turistificación del borde costero, entre otros.

Este documento aborda estos dos últimos procesos, identificando un caso que ha logrado mantener su hábitat y prácticas tradicionales, porque ha quedado alejado -por ahora-, de los circuitos de mayor demanda del capital y del crecimiento urbano; y otro donde la caleta se ha sumado a un circuito turístico, diversificando y adaptando sus prácticas y oficios a este nuevo mercado, generando con ello nuevas dinámicas sociales y urbanas.

El artículo se estructura en cuatro partes: la primera expone el contexto del neoliberalismo y sus efectos en las transformaciones socioespaciales de las caletas urbanas; la segunda, describe las principales transformaciones y estrategias de adaptación de las caletas de estudio ante los procesos identificados; la tercera discute las fragilidades y potencialidades de estos lugares como formas de hábitat y cultura sostenibles en el territorio costero. Finalmente se concluye con un análisis de los ciclos de evolución de las estrategias y transformaciones, corroborando la hipótesis planteada. 


\section{Neoliberalismo y transformaciones socio-espaciales en caletas urbanas}

Las caletas han sido históricamente asentamientos construidos por comunidades de pescadores artesanales y sus familias. Para ello, han configurado un hábitat singular asociado al mar, el oficio y la morfología y dinámicas del borde costero -en el caso de Biobío, el borde costero es bastante escarpado y poco llano, dando forma a una particular trama urbana de adaptación del hábitat al territorio- con una particular apropiación y significación del espacio. Esto define un habitar-caleta, expresado en prácticas de uso que configuran las caletas importantes lugares geográficos y simbólicos (Saavedra y Macías, 2012; Sáez, 2004; Orellana y Díaz; 2016).

Junto a ello, estos asentamientos han estado históricamente tensionados por amenazas naturales y antrópicas. Las naturales provienen principalmente de tsunamis y terremotos, que han moldeado el borde litoral, y las formas de habitarlo. Las antrópicas, dependen principalmente de presiones económicas, como la pesca industrial, y el desarrollo urbano, expresado en la privatización del borde costero (Hidalgo et al., 2016).

El estado neoliberal (Harvey, 1973), instalado por la fuerza en Chile en la década de 1980, determinó que la toma de decisión sobre los territorios era definida principalmente por agentes privados en mercados liberados y abiertos al exterior (Andrade, Arenas y Guijón, 2008). Así, se instaló un régimen pesquero neoliberal, que argumentó que la pesca artesanal estaba agotando "los recursos comunes", poniendo en riesgo su preservación (Hardin, 1995; Ostrom, 2011).

Bajo este régimen se establecieron regulaciones para limitar la pesca artesanal, fomentando la explotación industrial de los recursos marinos. En este nuevo marco, se ha exigido a los pescadores cumplir cada vez mayores exigencias legales, lo que ha precarizado su actividad, (Morales y Gezán, 1986; Andrade et al., 2008; Zúñiga, Ramírez y Valdebenito, 2010), haciéndola vulnerable a la lógica de mercado (Orellana y Díaz, 2016) y poniendo en riesgo su sostenibilidad.

Esto se ha agudizado en las últimas décadas, con el creciente interés del capital global sobre los bordes costeros. En el marco de un Neoliberalismo expansivo, estos territorios se han vuelto objetos de deseo para el desarrollo industrial a gran escala, especialmente para proyectos portuarios y energéticos (Ávalos, 2006; Andrade et al., 2008), como también para el desarrollo turístico e inmobiliario, en el marco de la producción neoliberal de la ciudad, especialmente para demandas de segunda o tercera residencia (Hidalgo et al., 2016).

La escala de estos proyectos, sus necesidades y externalidades han generado diversas transformaciones socio-espaciales en los asentamientos pesqueros artesanales, entendidas como procesos dialecticos de pugnas entre capital y comunidades costeras artesanales que se articulan. Entre ellos se distinguen:

- Crecientes procesos de expulsión e invisibilización de las caletas (Sabatini, Worlmald, Sierralta, y Peters, 2010), transformando en algunos casos a éstas en zonas residuales o de sacrificio (Tironi y Rodríguez, 2017; Camus, Hidalgo, Pérez y Muñoz, 2016).

- Deterioro y precariedad urbana, por término o disminución de la actividad productiva tradicional. Algunos de estos asentamientos presentan conflictos de propiedad, saneamiento básico o urbanización (Avalos, 2006; Andrade, 2008).

- Conflictos y tensiones sociales por el uso del borde entre pescadores artesanales y representantes de grandes proyectos con infraestructuras de gran escala -intercomunal y metropolitana- como autopistas, trazados ferroviarios, desarrollos portuarios $y$ energéticos (Sáez, 2004; Alcalá, 2011; González, Cruz, Hernández y Medellín, 2011; Tironi y Rodríguez, 2017).

- Diversificación e hibridación productiva, dada la escasez de recursos marinos tradicionales, derivada de nuevos entornos económicos y políticos, que ha derivado en un borde costero urbano mixto, donde coexisten modelos productivos pesqueros artesanales, y modelos productivos de cultura sustentable moderna en construcción.

- Gentrificación costera, en tanto los bordes costeros comienzan a ser objeto de interés para el desarrollo de proyectos urbanos a la vez que concebidos como áreas de riesgo. Así, las comunidades pesqueras son presionadas a abandonar sus espacios (Hidalgo 2016; Camus et al., 2016), en base a los riesgos de las últimas catástrofes naturales y los diversos estímulos y condicionantes estatales para la inversión privada en ellos. 
- Turistificación y patrimonialización, que ha surgido como respuesta a la reducción de los recursos pesqueros y las diversas presiones del capital a estas comunidades, que ha hecho que varias caletas se reorienten al turismo. En este sentido, el Estado neoliberal reduce las tensiones del borde y la disputa por los bienes comunes con diversos incentivos para que las caletas construyan su hábitat e identidad en un relato y escenografía, ofrecida como producto turístico junto a gastronomía de productos marinos extraídos de otras zonas (Massó, 2016; Giménez, 1997; Urteaga, 2013; Ladrón de Guevara, Gaete y Morales, 2003).

Todas estas transformaciones expresan lo que Harvey (2007) denomina crecimiento geográfico desigual, cimentado en desigualdades estructurales que el capital utiliza para su consolidación, y que, en este caso, exponen relaciones dialécticas entre capital global y local por apropiarse de la gestión del espacio del borde costero y los recursos marinos. No obstante, el capital no se despliega en el espacio de manera lineal, las caletas no son asentamientos estancos, sino espacios sociales (Lefebvre, 2013) donde se articulan relaciones que se proyectan en el espacio, por ello las transformaciones antes vistas son expresión de las diversas estrategias -visibles y solapadas- que las comunidades han desarrollado para adaptarse, resistir o re articular su hábitat e identidad frente a las demandas del capital, configurando sus propias formas de espacialidad. Analizar cómo estos diversos procesos espaciales se han desplegado de manera particular en los casos de estudio, o qué nuevas formas de espacialidad han desarrollado, es el interés de este trabajo.

\section{Enfoque metodológico}

El enfoque metodológico de la investigación es mixto, con énfasis en lo cualitativo. Conjuga técnicas de diferentes disciplinas de las ciencias sociales, para configurar un enfoque de análisis evolutivo socio-espacial. Se analizan fuentes bibliográficas diversas, como documentos históricos, planos, fotografías, libros, etc. Junto con lo anterior se utilizan instrumentos públicos como el Plan Regulador Comunal (PRC) vigente y la Ordenanza local, entre otras. Se realizan cinco visitas a terreno para levantar información de archivo y realizar entrevistas semi estructuradas a funcionarios municipales, habitantes de las caletas y dirigentes sociales. Se elaboran Mapas de interpretación, sobre el plano base del Plan Regulador Comunal vigente, en el que se dibujan las fases de ocupación de las caletas, distinguiendo periodos de acuerdo a los principales hitos o eventos de transformación socio espacial de ellas. Posteriormente, se extraen del Mapa los principales hitos de transformación, y con ellos se elabora una Línea de tiempo socio-espacial, que permite visualizar el proceso evolutivo de transformación. En otros mapas y esquemas se sintetizan las principales estrategias de adaptación de las caletas a las transformaciones ocurridas.

\section{El Área Metropolitana de Concepción}

La investigación se realizó en Tomé, una de las ocho ciudades litorales del Área Metropolitana de Concepción (AMC), donde se identifican, preliminarmente, cerca de 20 caletas, como se ilustra en la Figura 1.

Los casos escogidos representan diferentes expresiones de vinculación caleta-ciudad, como se muestra en la Figura 2, lo que podría determinar diferentes niveles de exposición y vulnerabilidad a transformaciones, y estrategias de adaptación. Los Bagres se ubica en el extremo norte de la bahía de Tomé, muy cercana al centro urbano. Su nombre proviene del Lafkenche, que nombra el rastrojo de las olas (Saavedra, 2006). Cocholgüe, por su parte, se ubica en el exterior de la bahía, a $3,5 \mathrm{~km}$ al noroeste del centro urbano. Su nombre significa en mapudungun "Agua de cholgua" (Saavedra y Macías, 2012) y se divide en Caleta Grande, con vocación extractiva de productos marinos, donde se ubicaba la mayoría de las viviendas; y Caleta Chica, con vocación turística, que incluye la playa, cocinerías y restaurantes (Morales y Romero, 1981). 


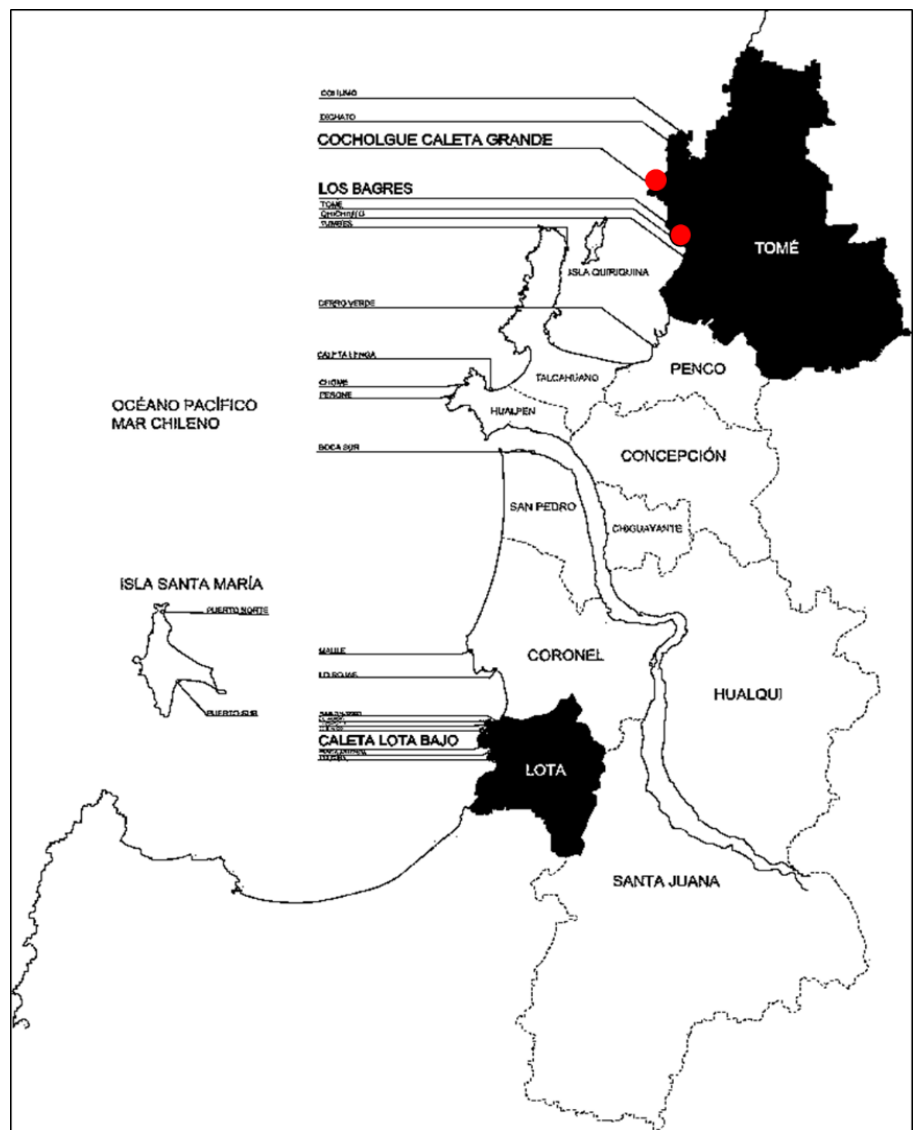

Figura 1. Localización de caletas en el Área Metropolitana de Concepción y casos de estudio. Fuente: Elaboración propia.

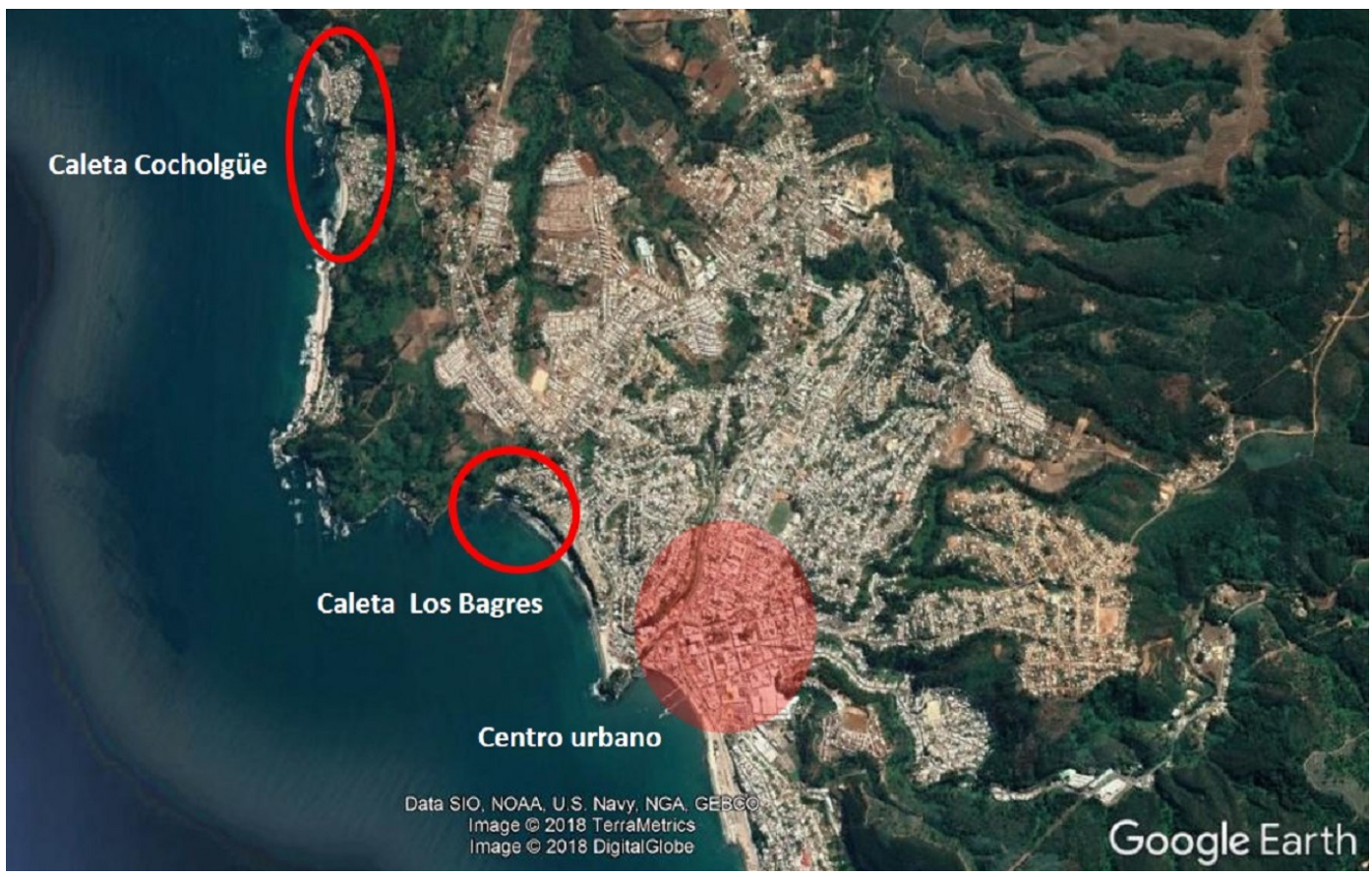

Figura 2. Localización de los casos de estudio en la ciudad de Tomé.

Fuente: Elaboración propia, sobre Google Earth, 2017. 
Evolución y transformaciones socio-espaciales en caletas Los Bagres y Cocholgüe, Tomé

Los principales hitos que han transformado socio espacialmente a las caletas, permiten distinguir un ciclo fluctuante en los casos de estudio.

En el caso de Los Bagres, se identifican comunidades originarias asentadas en la bahía ya en 1760 . En el siglo XVII se instalaron familias de criollos, por disponibilidad de espacio y productos marinos. Las primeras viviendas se construyeron cercanas a la orilla, donde se vivía y trabajaba; y desde aquí los habitantes se desplazaban por la playa y el mar. Se desarrolló un sistema familiar colaborativo, con tareas colectivas, desde la construcción de balsas o botes, la pesca, la recolección, hasta el tratamiento de los productos (Sanhueza, 2012).

En 1858, Tomé obtuvo el grado de Puerto Mayor, iniciándose un incipiente proceso de urbanización de la ciudad (Miranda, 1926). En 1902 ya se había urbanizado todo el frente de mar hasta el sector el Morro por el norte. En ese periodo caleta los Bagres era un reducto apartado del centro urbano por el cerro Navidad. Posteriormente, se instalaron familias tradicionales de pescadores, como los Ortiz, Salgado, Macías, Cartes y Reyes, cuya descendencia se mantiene (Sanhueza, 2012). En la década de 1920, la llegada del ferrocarril y el desarrollo fabril, determinó un notable crecimiento urbano, atrayendo gran cantidad de visitantes, especialmente en verano, a sus playas y balnearios, como El Morro, inaugurado en 1925. Esto aumentó considerablemente la demanda de productos marinos, entre los que destacaban las apancoras (centollas magallánicas), que eran cocidas en barriles de lata a la orilla de la playa por los pescadores, derivando en el apodo de Los Bagres como La Apancorera. Los ingresos de los habitantes de la caleta aumentaban y los pescadores se sentían orgullosos de trabajar con "la mar" (Miranda, 1926).

En 1931 se inauguró el casino Navidad, que junto con actividades como el "Paseo Veneciano" por la bahía de Tomé, posicionaron a caleta los Bagres como parte de la imagen urbana. Asimismo, el aumento demográfico que conllevó el proceso de industrialización, determinó la urbanización del Cerro Navidad y creación de nuevos barrios, por lo que en 1958 se construyó la Población el Colo junto a la caleta (Figueroa y Figueroa, 2015; Sanhueza, 2012). Esto motivó la organización de sus habitantes para instalar el tendido eléctrico y construir la escalera que permitió la accesibilidad cerro-mar, contribuyendo al sistema productivo y socio espacial de la caleta. Más tarde, se construyó un varadero para dar mejor accesibilidad de los botes al mar, fomentando el vínculo con otras caletas cercanas.

Luego de consolidarse como caleta con cierto grado de urbanización entre las décadas de 1960 y 1970, Los Bagres sufrió un progresivo menoscabo, tanto a nivel productivo como de articulación con la ciudad. La desaparición del ferrocarril y el proceso de desindustrialización de Tomé, implicaron un progresivo descenso de la actividad pesquera y del asentamiento. Un ejemplo de ello, es que en los planes reguladores de la ciudad, la caleta no aparece identificada como tal, y no se consideran proyectos para su revitalización socioeconómica y espacial, lo que incide en su precariedad.

En 2002, la construcción del varadero permitió 6 potenciar la caleta como centro de venta y punto turístico, sin embargo, y de acuerdo a lo mencionado por los pescadores, Los Bagres no se conoce como espacio turístico activo. La disminución de cuotas de pesca artesanal y de especies, ha obligado a los pescadores a recorrer cada vez mayores distancias para obtener los productos, como se muestra en la Figura 3, lo que vuelve incierta la sostenibilidad de la actividad, y por ende, del modo de vida que le es propio.

Hoy en día, la caleta representa un sector precarizado del pericentro urbano de Tomé, sin equipamientos, por lo que sus habitantes se desplazan principalmente hacia el Cerro Navidad y el centro para suplir necesidades de comercio, salud y educación. A nivel de planificación urbana, el sector ha sido calificado como área de riesgo (Plano Regulador de Tomé, 2007), lo que viene a sumarse a la afectación y deterioro. La síntesis se presenta en la Figura 4. 


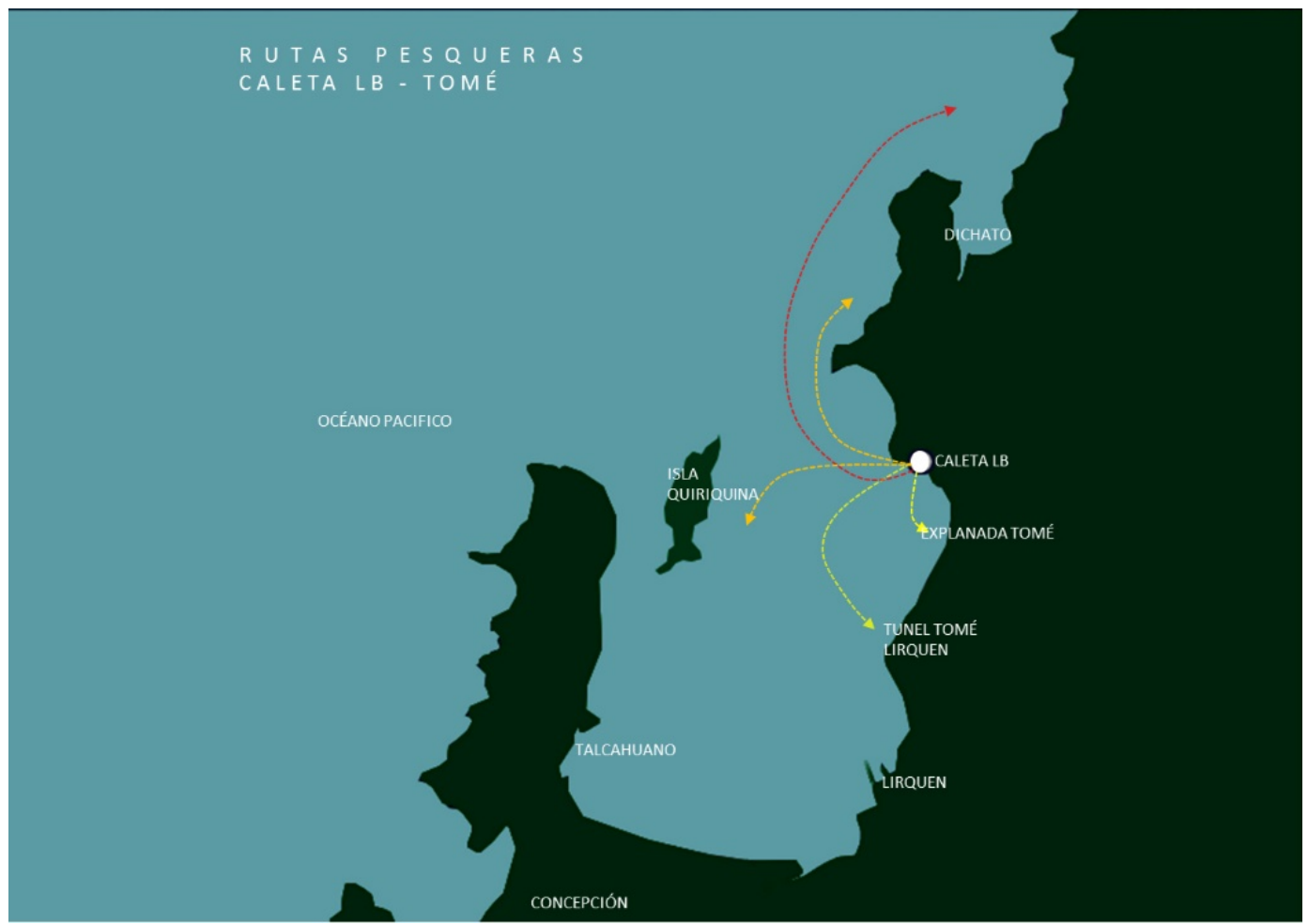

Figura 3. Esquema de las rutas marinas de pescadores de Los Bagres Fuente: Elaboración propia, 2017.

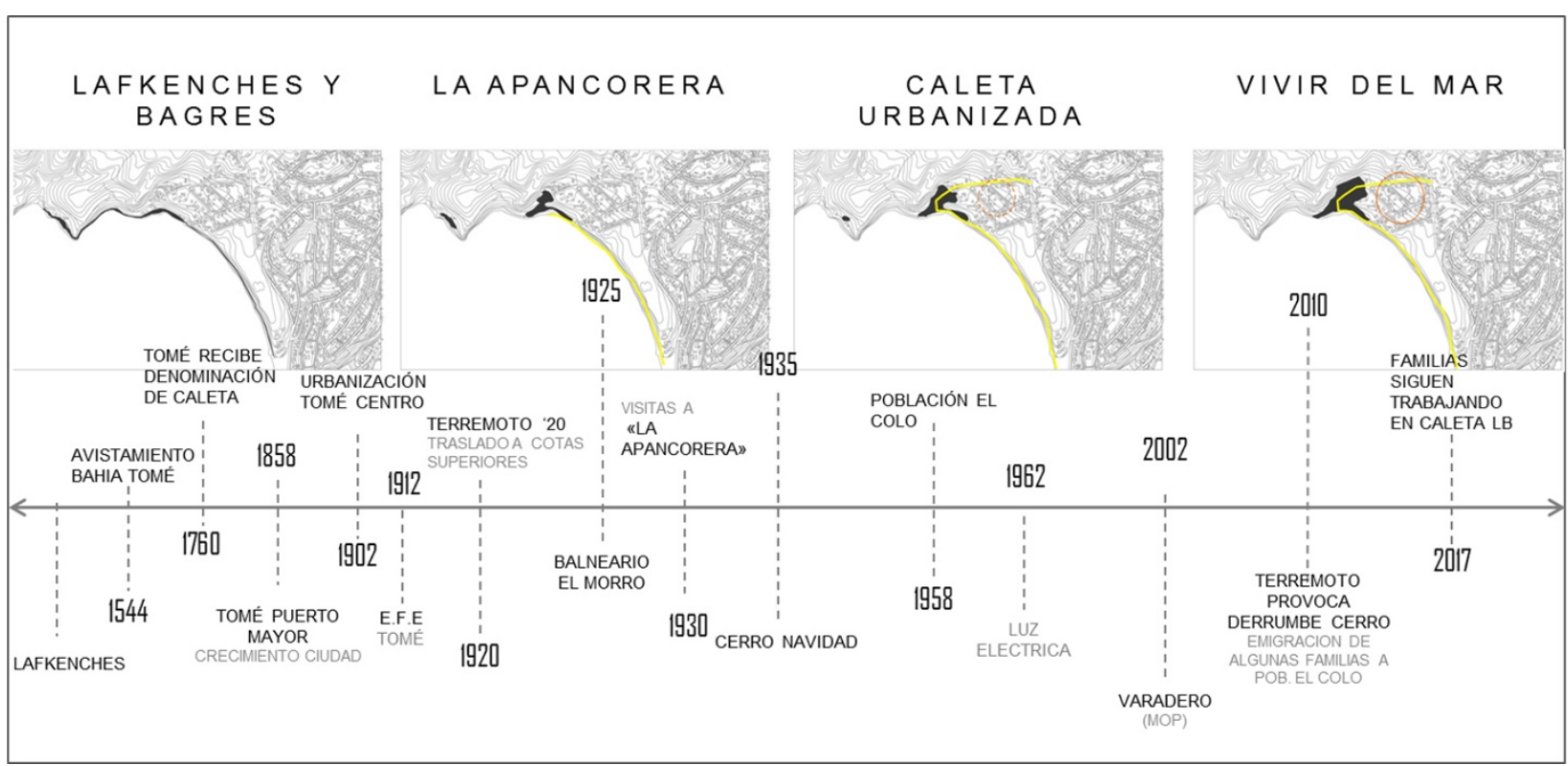

Figura 4. Proceso evolutivo de caleta Los Bagres.

Fuente: Elaboración propia, 2017.

En el caso de Cocholgüe, se tienen antecedentes de asentamientos en la Caleta Grande hacia 1890 (Morales y Romero, 1981), coincidiendo con el auge de la empresa textil en Tomé. Inicialmente se accedía por botes, canoas y pequeñas embarcaciones, ya que su entrada se encontraba protegida por un extenso cordón de rocas marinas. Estas condiciones geográficas determinaron el aislamiento, ruralidad y precariedad de la actividad 
pesquera, con balsas confeccionadas por los habitantes, con cuatro palos anudados con tiras de cuero (Cid, 2003).

El asentamiento original fue configurado por clanes familiares, como los Rodríguez, Méndez, Macaya y Andrade (Morales y Romero, 1981), que se localizaron en unas 15 viviendas situadas en el borde costero, orientadas al mar, donde actualmente se encuentra el sector de La Planchada. Toda la comunidad se dedicaba a labores de pesca y complementarias, lo que determinaba gran organización, lazos familiares e identidad local. Las viviendas eran espacios comunitarios, donde todos podían acudir, ya que cada familia cumplía un rol específico en torno a la pesca, provocando una mixtura entre lo público y lo privado. La materialidad era precaria, y utilizaban las laderas detrás de ellas para cultivar vegetales en terrazas. La caleta no contaba con servicios básicos como electricidad, agua potable o alcantarillado. Cid (2003) señala que la falta de alcantarillado ha sido un problema hasta la actualidad, ya que las aguas servidas aun circulan por canaletas. Para iluminarse utilizaban lámparas de querosene.

Durante la primera mitad del siglo XX el crecimiento de la caleta fue moderado, con incremento de viviendas en las laderas de los cerros, que derivó en la construcción de la primera escalera pública en 1960, que atravesaba el camino inicial serpenteante, internándose entre las viviendas, y generando pequeños espacios comunitarios, por lo que se transformó en la principal vía pública del poblado, hasta la actualidad, según Morales y Romero (1981).

Las nuevas viviendas respetaron la organización espacial preexistente, lo que favoreció la mantención de las dinámicas productivas, favoreciendo el traslado de productos marinos, principalmente luga y merluza, desde la playa a las viviendas. La falta de alcantarillado derivó en la implementación de un canal abierto para ello, junto a la escalera (Cid, 2003). Por su parte, el agua potable se instaló en lo alto del cerro, por medio de tres llaves, generando instancias de reunión comunitaria.

En la década de 1970 se construyó el faro, al norte del poblado, conectado por un sendero, que se transformaría más tarde en un elemento icónico y destino turístico local. Ese mismo año se dotó de electricidad, lo que permitió la conservación y posterior venta de productos marinos en gran cantidad, especialmente la merluza austral, elevando a Cocholgüe como la mayor productora nacional (Morales y Romero, 1981). Esta era almacenada en las viviendas, y colgada en los cierres perimetrales, constituyendo un paisaje urbano único, con exposición de los implementos de pesca y la mercadería, que luego era vendida en las localidades cercanas. La playa también era usada para colgar la merluza seca y algas, transformándola en un patio de trabajo. Se sabe que "las algueras", mujeres dedicadas a la extracción y tratamiento de las algas (Donoso, Molina, Valdés y Ortiz, 2016), las llevaban a la caleta desde la isla Quiriquina, distante a unos $8 \mathrm{kms}$ al sur oriente de Cocholgüe.

Entre 1970 y 1980, la caleta se consolidó como asentamiento urbano. Se entregaron títulos de propiedad a las familias, y la Municipalidad de Tomé realizó el primer loteo respetando las viviendas preexistentes, generando un plano orgánico donde ningún lote era igual a otro, marcando las escaleras como calles de acceso hacia la playa.

En la década de 1980 se construyó un muro al borde de la playa, con aporte, tanto en mano de obra como en capital, de todos los pescadores, ya que sentían que era un bien común necesario para dar progresar como caleta, porque permitiría proteger los botes contra las mareas y otras actividades productivas. El plano superior del muro, llamado "la Planchada", se consolidó como un significativo espacio colectivo, una especie de plaza de la Caleta Grande, dado que permitía la realización de múltiples actividades, como celebraciones, reuniones, y patio de trabajo de algueras y pescadores. En época de celebraciones este espacio se limpiaba de todos los implementos de trabajo y se tiraban las barcazas a la mar, dejando el borde solo para tránsito de personas. Se decoraban las calles, se instalaba un escenario, y aunque no eran celebraciones masivas, permitían el vínculo con los habitantes de la Caleta Chica, que caminaban por la orilla hasta la Caleta Grande. La prosperidad y mejora en la calidad de vida fue un aliciente para la llegada de más población a la caleta. La pesca les proveía de tal forma que acumulaban mercadería para el invierno, cuando los habitantes permanecían en sus casas.

El cierre de las industrias textiles y la privatización del ferrocarril, a fines de la década de 1980, atrajo población a Cocholgüe, buscando dedicarse a la pesca artesanal. Las nuevas familias ocuparon el poco espacio llano disponible, 
y varias viviendas se construyeron en las laderas empinadas, rompiendo la organización espacial previa, además de generar riesgos para la habitabilidad comunitaria. En muchos terrenos se construyeron casas para los hijos de los residentes originales, generando pasillos estrechos entre las viviendas, sin soluciones sanitarias, generando barriales, suciedad y contaminación. Pese a ello, los entrevistados, recuerdan que este fue el mejor periodo en relación a la pesca, aunque las condiciones de habitabilidad hayan sido difíciles.

En 2005 se pavimentó el camino de acceso al poblado, proyecto esperado por décadas por los residentes, mejorando el transporte de productos, la conectividad de los habitantes hacia el centro urbano, y la atracción de visitantes, lo que fomentó el turismo de playa $y$ gastronomía marina, basada principalmente en la extracción y venta de merluza (Dirección de Vialidad Biobío, 2005). Ese mismo año se produjeron fuertes lluvias invernales que inundaron el poblado y generaron derrumbes en las laderas de los cerros, destruyendo varias viviendas. Esto motivó la declaración de la caleta como Zona de Desastre (Minvu, 2017). Gran parte de la población fue trasladada a la villa Esperanza de Cocholgüe, ubicada en la parte alta del poblado, entre la caleta y la ciudad de Tomé, en viviendas de un nivel, de $42 \mathrm{~m}^{2}$, como se ve en la figura 5 .

Posterior al terremoto y tsunami de 2010, el Plan Regulador de Tomé ha zonificado a Caleta Grande como Zona de Riesgo Inhabitable, acelerando el proceso de erradicación iniciado el 2006. La síntesis de la evolución espacial se muestra en la Figura 6.
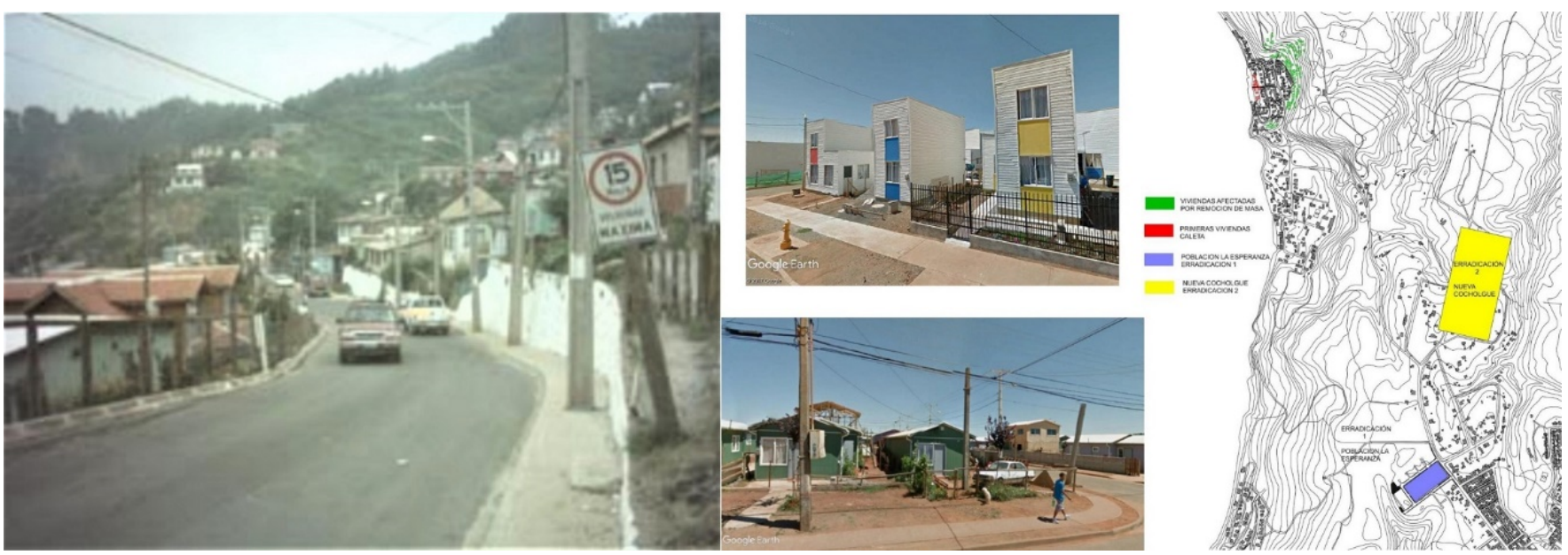

Figura 5. Vistas de Cocholgüe y villa Esperanza de Cocholgüe.

Fuente:http://biobio.vialidad.cl/noticias/resumen\%202005/tome\%20cocholgue_261205/tome\%20cocholgue201205.htm; y elaboración propia sobre google earth, 2017.
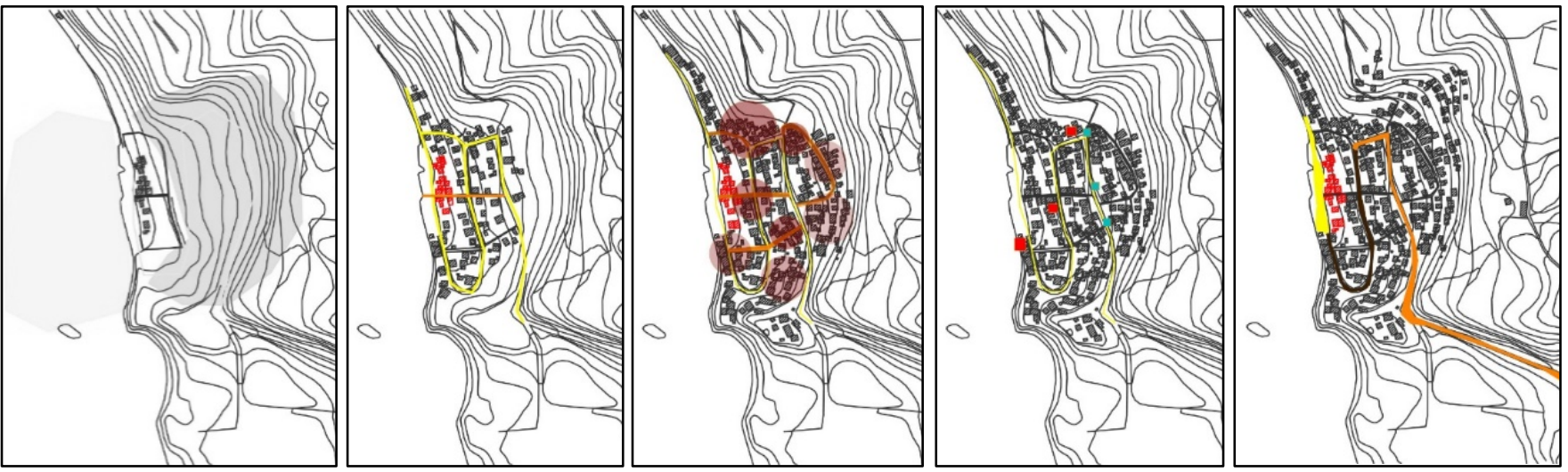

Figura 6. Síntesis del proceso de transformación urbana caleta Cocholgüe

Fuente: Elaboración propia, 2017. 
Actualmente la visión del municipio y la comunidad está orientada al turismo, diversificando su base económica (Plan de Desarrollo Comunal de Tomé, 20162020). Algunos habitantes han intentado poner en valor la caleta, desarrollando actividades de embellecimiento, como pintado de escaleras, construcción de mosaicos en el muro de La Planchada, etc. Aun así, muchas viviendas se encuentran en proceso de venta o arriendo, y han llegado nuevos residentes interesados en la conservación del patrimonio cultural e identidad local, sustituyendo el tejido social preexistente, pudiéndose observar incipientes procesos de gentrificación.

\section{Principales estrategias de adaptación socio-espacial de las caletas de estudio}

Preservación y diversificación productiva de productos marinos. En Los Bagres, solo una parte de la comunidad conserva la actividad pesquera artesanal, en base a recolección de apancoras y algas. Las recolectan en la bahía de Tomé, especialmente cuando hay buen clima y las venden principalmente a cocinerías del centro urbano. En Cocholgüe, en cambio, se ha diversificado la base económica, instalando cocinerías y restaurantes, y en las últimas décadas, arrendando casas y cabañas, especialmente en verano. Por su parte, el Estado ha creado programas de inversión para apoyar el desarrollo de pequeñas empresas en las caletas, fortaleciendo el desarrollo turístico y gastronómico. Ese mismo turismo que, a otra escala, ha permitido al capital colonizar el borde costero disminuyendo las resistencias por el deterioro de la actividad pesquera artesanal.

\section{Adaptación al territorio costero y a las presiones sobre}

él. En ambos casos estudiados se identifican estrategias comunes de adaptación al hábitat costero. En primer lugar, la apropiación del sitio geográfico, verificable en la instalación de viviendas en las laderas, muchas sobre pilotes; la creación de senderos de cota, que serpentean por las laderas, para la accesibilidad a la playa. En segundo lugar, se identifican estrategias de ocupación mixta de espacios de la caleta, como la apropiación de la playa para salida y llegada de botes, secado y manejo de productos, venta directa, y reunión colectiva; y la creación de infraestructuras funcionales que pasan a convertirse en espacios de significación colectiva y usos púbicos, como las escaleras, los muros de playa -Varadero, en Los Bagres y Planchada en Cocholgüe- y el faro en este último. Estas infraestructuras han derivado en espacios de soporte al desarrollo de prácticas tradicionales, que mezclan trabajo y vida en comunidad, propias de las caletas. En el caso de Los Bagres, es fácil reconocer que los principales usos del espacio son las circulaciones de acceso, el varadero, la cocina comunitaria y la capilla, tal como se muestra en la figura 7.

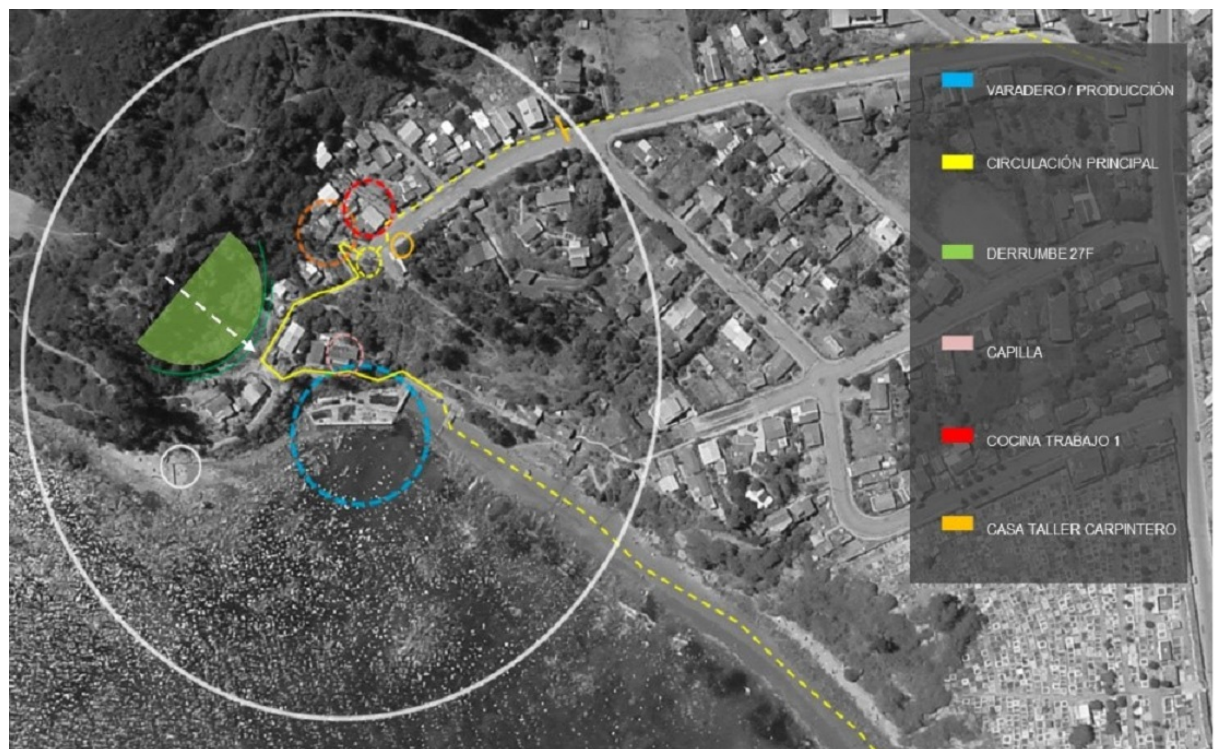

Figura 7. Esquema de usos en la caleta Los Bagres.

Fuente: Elaboración propia, sobre Google Earth, 2017. 
Adaptación de la residencia al entorno local y a la actividad pesquera artesanal. En ambos casos se observan viviendas escalonadas, que permiten las vistas sobre el horizonte, y diferencian los primeros niveles para actividades productivas -la cocina, bodega, etc.-, de los segundos niveles destinados a los dormitorios.

En el caso de Los Bagres, existen, además, una vivienda que es de uso colectivo para la limpieza y preparación de productos, que es usada mayoritariamente por las mujeres de la caleta; y la vivienda-taller de un pescador carpintero, instalada en la unión entre la escalera y la calle de acceso a la caleta, lo que permite que las embarcaciones puedan ser instaladas para reparación o descendidas por la escalera para su fácil botadura al mar.

En ambos casos se observan chifloneras -espacio retranqueado del acceso- que protegen de la lluvia y el fuerte viento norte invernal. La cocina amplia, la zona de guardado de herramientas y la accesibilidad inmediata a la circulación principal dentro de la caleta, son fundamentales en su rutina de trabajo, por lo que se incorpora directamente en la funcionalidad de las viviendas. La material principal es madera, tal como se observa en la figura 8.
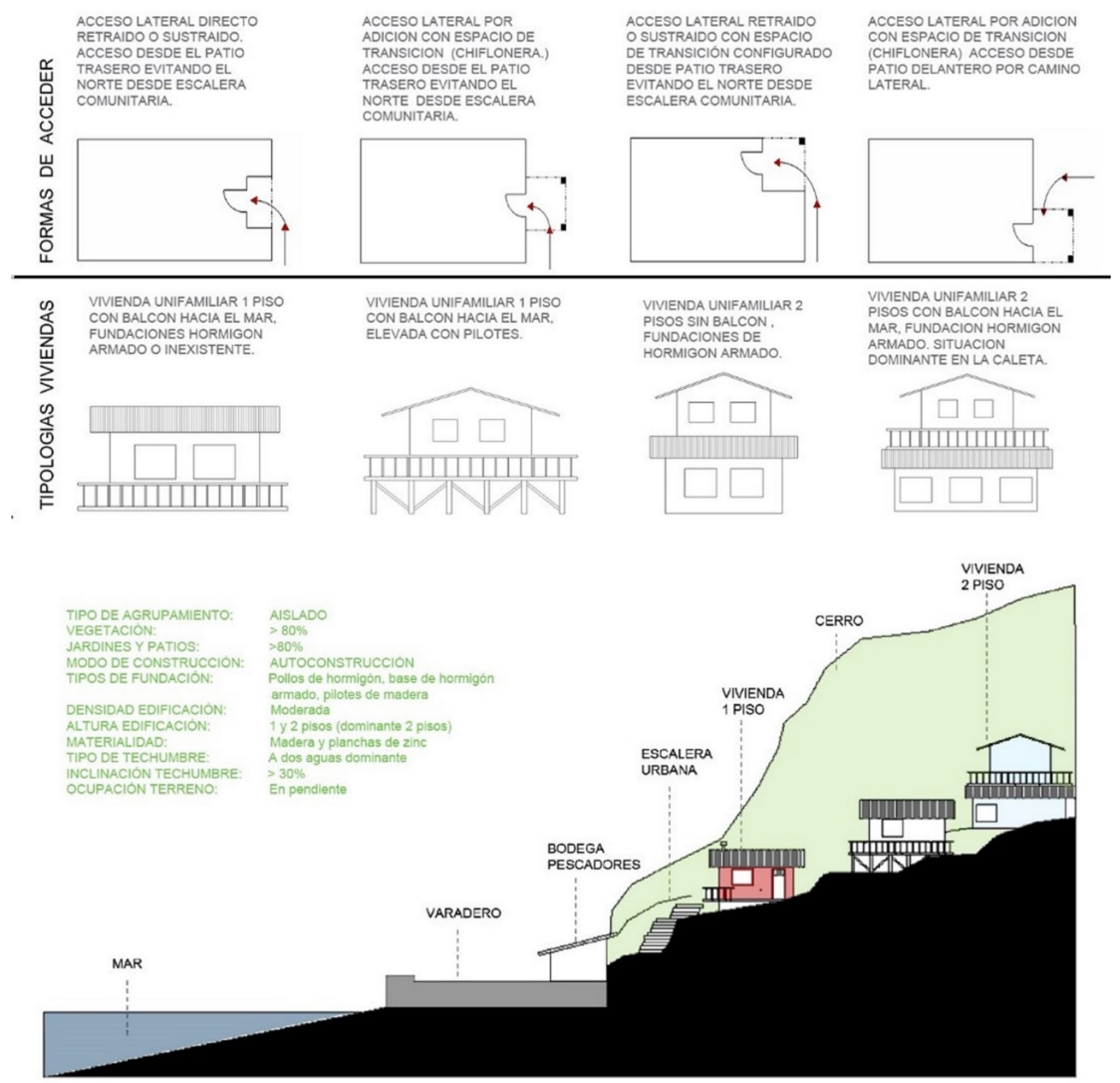

Figura 8. Tipologías y organización de viviendas en Los Bagres.

Fuente: Elaboración propia, 2017 
Por otra parte, la abundante vegetación del cerro y la pendiente, junto a su exposición al sur, les otorga frescor en el verano. En el caso de Cocholgüe, destaca también el uso de los cierres perimetrales de los terrenos, para secado y exposición de productos, y secado de ropa de trabajo y familiar.

\section{Discusión de resultados}

Los resultados obtenidos permiten extraer algunas invariantes comunes a los casos de estudio, a la luz de los objetivos planteados. Estas se han agrupado en cuatro tendencias principales.

\section{Fragilidad de las caletas como lugar para vivir y trabajar.} Una de las características principales de las caletas es su simbiosis espacial entre vida y trabajo. Esta se ha dado por empuje de los propios habitantes, y aun cuando han tenido la fuerza para dominar el mar y el espacio costero, en ambos casos los asentamientos son precarios (Morales y Gezán, 1986; Andrade et al., 2008; Magadán, 2015; Zúñiga et al., 2010). Esta precariedad se expresa en dos sentidos. Primero, en lo relativo a la dimensión material asociada a las viviendas y la urbanización. La mayoría de ellas de materialidad y estructura frágil, por lo que están en riesgo constante de sucumbir a los riesgos naturales, como también de adaptarse a las condiciones climáticas. Sería importante analizar estas formas de autoconstrucción, sus fortalezas y debilidades. La urbanización en ambos casos presenta rasgos de ruralidad, con calles de tierra, senderos sinuosos bordeando las cotas de los cerros, y servicios básicos de baja calidad.

Segundo, en lo relativo a la dimensión inmaterial, las tensiones y presiones hacia el oficio y el lugar asociada a la posición de estas comunidades en un escenario de cambio global, ha generado un deterioro del capital social asociado a estas comunidades con lo cual se hace complejo la defensa del territorio y de sus formas de habitar. Las presiones y demandas del crecimiento urbano en el borde costero del Área Metropolitana de Concepción conlleva que este pueda transformarse en un polo de desarrollo inmobiliario, al estilo de lo ocurrido con regiones como Valparaíso o Atacama (Hidalgo et al., 2016). Pese a estas fragilidades, aun se observa en ambos casos, la conservación de formas de habitar colectivo, expresadas en la mantención de espacios, formas de habitar y trabajar que son propias de comunidades cohesionadas, aun cuando se observan procesos creciente de abandono del oficio y de perdida de la comunidad. En la actualidad la simbiosis inicial vida-trabajo se está rompiendo, porque las estrategias desarrolladas desde agentes externos están presionando la erradicación de las comunidades costeras con residencia permanente, de ingresos bajos para que dejen sus espacios. Cuestión que se contradice con operaciones promovidas desde la invasión privada, aprobadas por los entes públicos municipios, Seremi MINVU-, en forma de inversiones inmobiliarias de estándar de ingresos medios y altos. Como es el caso de Santa Beatriz en Bellavista Tomé, Pingueral, etc. Seria relevante recoger estas diferenciales formas que tiene el Estado de asumir el riesgo en las poblaciones de borde y las consecuencias de ello para la sustentabilidad del borde costero.

Preservación e instrumentalización del patrimonio pesquero artesanal. En el caso de los Bagres, los habitantes, pese a tener aún un fuerte sentido de arraigo, no ven con claridad que puedan seguir desarrollando la actividad, no solo por escasez de recursos y lejanía de los lugares de obtención, sino porque no perciben de parte de los actores públicos el apoyo necesario para seguir adelante. No obstante, el no tener tanta visibilidad y accesos complejos ha permitido que los Bagres exista aún una comunidad fuertemente cohesionada que conserva aún algunas de sus prácticas tradicionales e identidad. En el caso de Cocholgüe, se observa una pérdida importante de arraigo e identidad al oficio y al lugar, ya sea por la disminución del recurso, como también por los procesos de erradicación vividos a partir del 2010. Parte importante de los pescadores tradicionales de la caleta ya no viven ahí y no hay población que desempeñe el oficio. Pese a ello hoy Cocholgüe es parte de los programas de turismo patrimonial asociados a las caletas, y los habitantes ven en la patrimonialización del oficio y el lugar la posibilidad de mantener la caleta, aunque ya en la práctica no funcione como tal. En este sentido se da un proceso de patrimonialización instrumental del lugar y sus prácticas identitarias. El patrimonio se configura en un recurso que busca construir lo que ya no está para darle rentabilidad a través de los mercados del turismo. Resultaría interesante analizar los efectos que tienen realmente estos discursos 
para revertir el deterioro económico de la comunidad y la erosión de la identidad y el oficio, o bien pasan a constituirse en una nueva forma que tiene el capital de colonizar estos espacios generando procesos incipientes de gentrificación y expulsión. El acervo de capital social existente se configura como una variable relevante para orientar estos procesos en u otro sentido (Giménez, 1997; Urteaga, 2013; Ladrón de Guevara et al., 2003).

Desplazamiento y gentrificación. En ambos casos, Estado y Municipio han forzado el desplazamiento de los habitantes, a partir de eventos como inundaciones, derrumbes, terremoto y tsunami. En Los Bagres han sido erradicados a un sector cercano, lo que ha permitido que los pescadores no pierdan su vínculo con el oficio y el lugar, manteniendo una itinerancia adaptativa entre la nueva y original residencia. En Cocholgüe, en cambio, han sido desplazados a una villa a más de $3 \mathrm{~km}$ del asentamiento original, por lo que ha sido muy difícil para los pescadores sostener el oficio pesquero y la vida comunitaria. Ello ha inducido sustitución social e incipiente gentrificación, que motivan a repensar un futuro posible para esta comunidad. Junto a ello, la caleta está siendo entendida como reducto de identidad litoral, lo que también constituye una amenaza, al ser entendida ésta como algo que debe forzarse, induciendo una fuerte turistificación, que desarticula las prácticas tradicionales asociadas a la pesca y recolección, y las sustituye por actividades de soporte a los servicios de turismo litoral (Massó, 2016)

Articulación v/s Integración urbana. Los niveles de integración urbana de las caletas muestran una relación ambivalente con su exposición a las demandas del capital por su territorio. En Los Bagres, su ubicación al borde de una ladera empinada, la esconde de los circuitos del capital industrial o inmobiliario, no obstante, se encuentra bien articulada al tejido urbano, e integrada a la dinámica urbana. En Cocholgüe, su lejanía del centro urbano y su menor articulación a éste, parece haber favorecido su intervención desde el Estado y el Municipio, dejándola expuesta a la acción transformadora radical. La declaración de zona de riesgo que la afecta parece un proceso irreversible.

Estas tendencias se pueden observar en la siguiente síntesis (tabla 1).

Tabla 1. Síntesis de tendencias a partir de los resultados.

\begin{tabular}{|c|c|c|}
\hline Tendencias & Los Bagres & Cocholgüe \\
\hline $\begin{array}{l}\text { Fragilidad de las caletas como } \\
\text { lugar para vivir y trabajar. }\end{array}$ & $\begin{array}{l}\text { La fragilidad se expresa en alta precariedad del hábitat. } \\
\text { Baja calidad constructiva de las viviendas. Espacios } \\
\text { públicos autoconstruidos. Insalubridad. Escasa } \\
\text { sostenibilidad de la actividad pesquera artesanal. }\end{array}$ & $\begin{array}{l}\text { Mayor calidad del hábitat, mejor calidad } \\
\text { constructiva de las viviendas y espacios públicos. } \\
\text { Escasa sostenibilidad de la actividad pesquera } \\
\text { artesanal. }\end{array}$ \\
\hline $\begin{array}{l}\text { Preservación e } \\
\text { instrumentalización del } \\
\text { patrimonio pesquero artesanal. }\end{array}$ & $\begin{array}{l}\text { Por su localización, los elementos identitarios más } \\
\text { reconocidos por la comunidad han sido invisivilizados para } \\
\text { las demandas del capital. }\end{array}$ & $\begin{array}{l}\text { Es potenciada como expresión del patrimonio } \\
\text { pesquero, aun cuando ya prácticamente no hay } \\
\text { desarrollo de la actividad. Instrumentalización del } \\
\text { patrimonio. }\end{array}$ \\
\hline Desplazamiento y gentrificación & $\begin{array}{l}\text { Alto porcentaje de población erradicada a otro sector de } \\
\text { la ciudad, post terremoto } 2010 \text {. } \\
\text { Algunas viviendas preexistentes se usan como residencia } \\
\text { estacional, en época de mejor pesca, y para arriendo, en } \\
\text { verano. }\end{array}$ & $\begin{array}{l}\text { Casi toda la población erradicada a otro sector de la } \\
\text { comuna, posterior a } 2006 \text { y } 2010 \text {. } \\
\text { Muchas viviendas deshabitadas se arriendan en } \\
\text { verano o están en proceso de venta. }\end{array}$ \\
\hline $\begin{array}{l}\text { Articulación } \\
\text { urbana }\end{array}$ & $\begin{array}{l}\text { La caleta se encuentra articulada a nivel físico como parte } \\
\text { de la trama del pericentro urbano de Tomé. } \\
\text { Sin embargo, no se encuentra integrada } \\
\text { socioeconómicamente a la dinámica urbana. }\end{array}$ & $\begin{array}{l}\text { La caleta se encuentra articulada a nivel físico, } \\
\text { aunque alejada del centro urbano. } \\
\text { Se encuentra medianamente integrada } \\
\text { socioeconómicamente a la dinámica urbana. }\end{array}$ \\
\hline
\end{tabular}

Fuente: Elaboración propia. 


\section{Conclusiones}

En relación con la pregunta de investigación, fue posible identificar procesos específicos de transformación de las caletas de estudio, y estrategias de adaptación a estas transformaciones.

En lo relativo a las transformaciones, se identificó un ciclo que incluye origen, crecimiento, auge y deterioro. En el origen se reconoce la instalación del sitio pesquero, que da paso a la formación de un asentamiento. En el crecimiento se reconoce la ampliación del poblado por la existencia de recursos que permiten la vida en comunidad. En el auge se identifica que la caleta se urbaniza, generando infraestructuras funcionales que se transforman luego en espacios públicos y colectivos de significancia comunitaria e identidad local. Este auge genera sobre ocupación de las caletas, y riesgos ambientales a escala local. Al sobrevenir la merma del recurso pesquero, por implantación del modelo de pesca industrial y factores político-ambientales, se produce el deterioro de la actividad, que acarrea un deterioro del poblado, poniendo en crisis la sostenibilidad del modelo de vida comunitario. En el caso de Cocholgüe, además, forzado por procesos de desplazamiento de la población.

En lo relativo a las estrategias de adaptación, cabe destacar el caso de Los Bagres, que al ser absorbida por la ciudad se encuentra en una menor exposición ante decisiones radicales como la que de erradicar la población, en el caso de Cocholgüe.

En relacion con la hipótesis que planteaba que las caletas son hábitats fuertemente tensionados por tres procesos fundamentales de transformación, los resultados evidenciaron que efectivamente la demanda del capital industrial a gran escala, el desarrollo urbano de corte neoliberal, y los procesos de turistificación del borde costero, son los procesos que han impactado con mayor fuerza la condición de las caletas analizadas.

En el caso de los Bagres, no obstante, los dos primeros procesos son los que más han impactado en su transformación e articulación socio-espacial. La pesca industrial y los efectos de la misma han significado aumentar el tiempo de recorrido para obtener los productos de la pesca y ha implicado la merma de los mismos, ello ha conllevado también el ampliar las actividades productivas hacia la recolección. El crecimiento urbano les ha implicado dotarse de cierta infraestructura urbana básica, pero no ha mejorado su calidad de vida, persistiendo a lo largo del tiempo una fuerte precariedad socio-espacial.

En el caso de Cocholgüe, la pesca industrial ha disminuido considerablemente sus recursos marinos tradicionales, ello ha implicado la diversificación hacia el turismo, migración, pérdida de arraigo y desarticulación de la comunidad.

Respecto a los procesos de adaptación, la investigacion mostró diferentes resultados. En el caso de Los Bagres se sabe que aun se mantiene la actividad, no obstante desarrollan una residencia itinerante entre el sector donde fueron desplazados y la caleta, especialmente en la epoca de verano. En el caso de Cocholgüe, la comunidad sucumbió a la presión por desplazarlos y la actividad casi ha desaparecido, frente a ello el turismo y la patrimonialización del oficio y su habitat se han constituido en un recurso para la obtención de ingresos, no obstante se observa una instrumentalización del discurso más que una construcción patrimonial arraigada en el territorio .

En síntesis, pese a sus similitudes, en tanto dinámicas productivas y socioculturales, cada caleta es una comunidad particular que ha construido sus prácticas e identidad en función de los recursos existentes en su territorio. Ello ha generado que cada asentamiento desarrolle distintas estrategias de adaptación a los cambios naturales y antrópicos. No obstante, la asimetría en la distribución de los usos de borde y del mar por actores privados y públicos, abre interrogantes sobre la sostenibilidad y permanencia de estos asentamientos en el futuro. Los casos analizados, nos abren diversas interrogantes sobre la articulación caleta-desarrollo urbano, las cuales esperamos responder en futuras líneas de investigación [B] 


\section{Referencias}

Alarcón, M. (2016). Transformación del frente portuario de Talcahuano: Oportunidades para la integración urbana. En Hidalgo, R., Santana, D., Alvarado, V., Arenas, F., Salazar, A., Valdebenito, C. y L. Álvarez. (2016). Las costas del neoliberalismo. Naturaleza, urbanización y producción inmobiliaria (144-170). Santiago de Chile: Instituto de Geografía, Pontificia Universidad Católica de Chile.

Alcalá, G. (2011). Pescadores en América Latina y el Caribe: Espacio, población, producción y política. Yucatán: UNAM-Facultad de Ciencias y Unidad Multidisciplinaria de Docencia e Investigación Social.

Andrade, B., Arenas, F., y Guijón, R. (2008). Revisión crítica del marco institucional y legal chileno de ordenamiento territorial: el caso de la zona costera. Revista de geografía Norte Grande, 41, 2348. https://dx.doi.org/10.4067/S071834022008000300002

Ávalos, P. (2006). Los impactos socio-espaciales en las caletas de pescadores artesanales de la comuna de Corral, en el marco de la legislación pesquera promulgada entre los años 1990-2005 (Tesis de pregrado). Universidad de Chile, Santiago, Chile. Recuperado de: http://www.tesis.uchile.cl/tesis/uchile/2006/avalos p/sources/avalos p.pdf

Camus, P., Hidalgo, R., Pérez, L., y Muñoz, E. (2017). ¡Defendamos Dichato! Bienes comunes y conflicto territorial en los espacios litorales chilenos. Revista de geografía Norte Grande, 68, 105-122. https://dx.doi.org/10.4067/S071834022017000300105

Camus, A., (2001). Biogeografía marina de Chile continental. Revista chilena de historia natural, 74(3), 587-617. https://dx.doi.org/10.4067/S0716$\underline{078 \times 2001000300008}$

Camus, P., Hidalgo, R., y Muñoz, E. (2016). Las disputas por el mar: bienes comunes, pescadores artesanales y pesca industrial. El caso de la caleta Cocholgüe en el litoral centro sur de Chile a mediados del siglo XX. Población \& Sociedad, 23(2), 91-114. http://www.scielo.org.ar/scielo.php?script=sci arttex t\&pid=S1852-85622016000200005
Cid, A. (2003). Habitar del espacio cotidiano: La unidad residencial del Concepción (Seminario de Título). Universidad del Biobío, Concepción, Chile.

Dirección de Vialidad Biobío. (2005). Concluye pavimentación del camino Tomé - Cocholgüe. Recuperado de: http://biobio.vialidad.cl/noticias/resumen\%202005/t ome\%20cocholgue 261205/tome\%20cocholgue2012 05.htm

Donoso, C., Molina, C., Valdés, D., y Ortiz, I. (2016). Pasado y presente de las algueras de Coliumo y Cocholgüe. Una descripción de la relación entre género, economía e identidad. Revista Antropología del Sur, 5, 85-102. http://dx.doi.org/10.25074/ads.v3i5.815.

Figueroa, N. y Figueroa, D. (2015). Visión integrada de la bahía de Concepción (Chile) para el fomento del turismo cultural. Revista Geográfica del Sur, 6 (9), 44 54. Recuperado de http://www.revgeosur.udec.cl/wpcontent/uploads/2016/10/FigueroaBurdiles Figueroa Verdugo 2015 RGS.pdf

Gajardo, C. y Ther, F. (2011). Saberes y prácticas pesqueroartesanales: cotidianeidades y desarrollo en las caletas de Guabún y Puñihuil. Chungará (Arica), 43 (1). http://dx.doi.org/10.4067/S071773562011000300014

Giménez, Gilberto (1997). La Sociología de Pierre Bourdieu. Instituto de Investigación Sociales de la Universidad Nacional Autónoma de México.

González, M., Cruz, K., Hernández, M. G., y Medellín, S. (2011). Nosotros somos del mar, el mar es nuestro. Tensión territorial en una comunidad pesquera del Golfo de California: el caso de Bahía de Kino, Sonora, México. En Graciela Alcalá (Ed.), Pescadores en América Latina y El Caribe: espacio, población, producción y política, Vol.1, (pp.71-103). Yucatán: UNAM-Facultad de Ciencias y Unidad Multidisciplinaria de Docencia e Investigación Social.

Hardin, G. (1995). La tragedia de los comunes. Gaceta Ecológica, 37, 38-48.

Harvey, D. (1973). Urbanismo y desigualdad social. Madrid: Editorial Siglo XXI. 
Harvey, D. (2007) Espacios del capital, hacia una geografía crítica. Madrid: Akal

Hidalgo, R., Santana, D., Alvarado, V., Arenas, F., Salazar, A., Valdebenito, C., y Álvarez, L. (Eds.) (2016). En las costas del neoliberalismo. Naturaleza, urbanización y producción inmobiliaria: experiencias en Chile $y$ Argentina. Santiago de Chile: Instituto de Geografía, Pontificia Universidad Católica de Chile.

Ladrón de Guevara, B., Gaete, N. Y Morales, S (2003) El patrimonio como fundamento para el desarrollo del capital social: el caso de un sitio arqueológico y Puntilla Tenglo. Revista Conserva, 7. Recuperado de http://www.dibam.cl/dinamicas/DocAdjunto 93.pdf

Lefebvre H. (2013) La producción social del espacio. Madrid: Capitan Swing,

Marcucci, D. (2014) Coastal resilience: new perspectives of Spatial and productive development for the Chilean caletas Exposed to Tsunami Risk. Procedia Economics and Finance, 18, 39-46. https://doi.org/10.1016/S2212-5671(14)00911-3

Massó, E (2016) ¿Giro decolonial en el patrimonio? La Liberation Heritage Route como alternativa poscolonial de activación patrimonial. Revista Pensamiento, 12(274), 1277-1295. https://doi.org/10.14422/pen.v72.i274.y2016.011.

Martner, C. (1999). El puerto y la vinculación entre lo local y lo global. EURE (Santiago), 25(75), 103-120. http://dx.doi.org/10.4067/S025071611999007500005

McGoodwin, J. (2002). Comprender las culturas de las comunidades pesqueras: Clave para la ordenación pesquera y la seguridad alimentaria. Roma: FAO.

Miranda, R. (1926). Monografía geográfica e histórica de la comuna de Tomé. Concepción: Imp. y Lit. Westcott \& Co. Sucesor Felix Armando Viaux A. Recuperado de http://www.memoriachilena.cl/archivos2/pdfs/MCO0 27800.pdf

Morales, C. y Romero, M. (1981). Tomé: Origen y desarrollo de su morfología urbana y funcionalidad (Tesis para optar al título de profesor de Estado en Educación Media en Historia y Geografía). Universidad de Concepción, Concepción, Chile.
Morales, H. y Gezán, L. (1986). La modernización de las pesquerías chilenas. Impactos sociales y ecológicos. Ambiente y Desarrollo, 2, 33-46.

Orellana, A. y Díaz, M. (2016). Las Caletas de Chile: Integración urbana y prevalencia de sus valores patrimoniales. El caso de la bahía de Coquimbo. Revista de Urbanismo, 34, 55-72. https://doi.org/10.5354/0717-5051.2016.40078

Ostrom, E. (2011). El gobierno de los bienes comunes. La evolución de las instituciones de acción colectiva. Ciudad de México: Fondo de Cultura Económica.

Plan de Desarrollo Comunal de Tomé (PRC), 2016-2020. Recuperado de http://static.tome.cl/pladeco tome 2016 2020.pdf

Sabatini, F., Wormald, G., Sierralta, C., y Peters, P. (2010). Segregación residencial en Santiago: Tendencias 1992 2002 y efectos vinculados con su escala geográfica. En F. Sabatini, R. Salcedo, G. Wormald y Cáceres, G. (Eds.), Tendencias de la segregación en las principales ciudades chilenas: Análisis censal 1982-2002 (pp.1942). Santiago: Pontificia Universidad Católica de Chile/Instituto Nacional de Estadísticas.

Saavedra, R. (2006). Visión histórica y geográfica de ToméChile. Concepción: Ediciones Perpelen.

Saavedra, G. y Macías, A. (2012). Tradición e innovación en las comunidades de pesca artesanal del sur de Chile: Hacia un enfoque reflexivo del desarrollo endógeno. Revista de Antropología Iberoamericana, 7(1), 33-64. https://doi.org/10.11156/aibr.070103

Sáez, M. (2004). ¿Desterritorialización del trabajo e identidad territorial? Pescadores Artesanales de la caleta de Cerro Verde Bajo de la comuna de Penco (Tesis para optar al grado de Sociólogo). Universidad de Concepción, Concepción, Chile.

Salinas, E. y Pérez, L. (2011). Procesos urbanos recientes en el Área Metropolitana de Concepción: transformaciones morfológicas y tipologías de ocupación. Revista de Geografía Norte Grande, 49, 7997. https://doi.org/10.4067/s071834022011000200006

Sanhueza, A. (2012). Historia de Tomé 1544-2010. Tomé: Autoedición. 
Servicio Nacional de Pesca y Acuicultura (2013). Caletas Pesqueras de Chile. Recuperado de: https://www.sernapesca.cl/index.php?option=com $r$ emository\&/temid $=246 \&$ func $=$ fileinfo\&id $=5654$

Tironi, M. \& Rodríguez I. (2017). Healing, knowing, enduring: Care and politics in damaged worlds. The Sociological Review Monographs, 65(2), 89-109. https://doi.org/10.1177/0081176917712874

Urteaga, E (2013). La teoría del capital social de Robert Putnam: Originalidad y carências. Reflexión Política, (15)29, 44-60.
Zúñiga, S., Ramírez, P., y Valdebenito, M. (2010). Medición de los impactos socio-económicos de las Áreas de Manejo en las comunidades de pescadores del norte de Chile. Latin American Journal of Aquatic Research, 38(1), 15-26. http://dx.doi.org/10.4067/S0718560X2010000100002 